CZASOPISMO INŻYNIERII LACDOWEJ, ŚRODOWISKA I ARCHITEKTURY JOURNAL OF CIVIL ENGINEERING, ENVIRONMENT AND ARCHITECTURE

JCEEA, t. XXXII, z. 62 (3/I/15), lipiec-wrzesień 2015, s. 357-364

Janusz RAK ${ }^{1}$

\title{
ZAPOMNIANE KONCEPCJE ZAOPATRZENIA RZESZOWA W WODE
}

\begin{abstract}
Wodociąg Rzeszowa liczy sobie 80 lat. Obecnie system zbiorowego zaopatrzenia w wodę posiada nadmiarowe zdolności produkcyjne. Związane to jest ze spadkiem zużycia wody wodociągowej. $\mathrm{Z}$ tego powodu na początku lat 90 - tych XX wieku zamknięty został pierwszy Zakład Uzdatniania Wody pracujący od 1934 roku. Jednak na początku lat 80 - tych XX wieku miasto zużywało więcej wody niż możliwości produkcyjne ówczesnych 3 Zakładów Uzdatniania Wody. Podjęte badania studialne nad zlikwidowaniem występujących deficytów wody. Nie można było dalej zwiększać poboru wody z rzeki Wisłok. Opracowano alternatywnie dwie koncepcje zaopatrzenia Rzeszowa w wodę z dwóch nowych źródeł:

- ujęcia wód podziemnych z 21 istniejących studni wierconych w podmiejskich miejscowościach Zaczernie - Bratkowice,

- przerzut wody z rzeki San ze zbiornika mającego być wybudowanym w miejscowości Niwiska koło Dynowa.

Projekty te nie zostały zrealizowane, chociaż 21 studni zostało wykonane, a woda z nich była badana podczas próbnych pompowań.
\end{abstract}

Słowa kluczowe: zaopatrzenie w wodę, koncepcje projektowe, charakterystyka systemu zaopatrzenia w wodę, alternatywne rozwiązanie dostaw wody

\section{Wstęp}

Rzeszów jest stolicą województwa podkarpackiego oraz siedzibą najważniejszych instytucji regionu. Liczba ludności w Rzeszowie wynosi 186000 (stan na 2014 rok). Miasto pełni funkcję głównego ośrodka przemysłowego handlowo-usługowego, kulturalnego i akademickiego. Sieć wodociągowa miasta Rzeszowa stała się faktem dopiero w latach trzydziestych XX wieku. W grudniu 1934 roku oddano do eksploatacji ujęcie powierzchniowe z Rzeki Wisłok i zakład uzdatniania wody (ZUzW) w sąsiedztwie zakładu WSK Rzeszów. Dzisiaj automatycznie odkręcając kurek niebieski lub czerwony i otrzymując strumień zimnej lub ciepłej wody nie zdajemy sobie sprawy, że 80 lat temu dopiero spełniało się marzenie ówczesnych mieszkańców Rzeszowa w tym zakresie.

\footnotetext{
${ }^{1}$ Janusz Rak, Politechnika Rzeszowska, al. Powstańców Warszawy 6, tel. 17 8651408, e-mail: rakjan@prz.edu.pl
} 
W obiekcie tym zaprojektowano i zrealizowano pierwsze w Polsce urządzenia do koagulacji wody. Wtedy wodociąg produkował $7500 \mathrm{~m}^{3} / \mathrm{d}$ wody, którą podawał do magistrali o długości $5 \mathrm{~km}$ i \& $325 \mathrm{~mm}$ ze zbiornikiem wyrównawczym końcowym $\mathrm{V}=600 \mathrm{~m}^{3}$. W 1951 roku rozpoczęto przedprojektowe badania wody rzeki Wisłok i w 1953 roku rozpoczęto budowę ZUzW w Zwięczycy. Autorami projektu technicznego byli inżynierowie Józef Migała i Józef Fiszer z BPBK w Krakowie [1]. W 1956 roku przekazano do eksploatacji ZUzW Zwięczyca o zdolności produkcyjnej $22000 \mathrm{~m}^{3} / \mathrm{d}$. Równocześnie zrealizowano $12 \mathrm{~km}$ magistrali wodociągowej $Q 400 \mathrm{~mm}$ oraz dwa zbiorniki wyrównawcze, końcowe o pojemności $1800 \mathrm{~m}^{3}$ każdy. W latach 1960-65 następuje rozbudowa ZUzW Zwięczyca do wydajności $36500 \mathrm{~m}^{3} / \mathrm{d}$. w latach 1968-1974 zrealizowano stopień wodny piętrzący wodę na rzece Wisłok mający w zamyśle zapewnić odpowiednią rzędną zwierciadła wody i gromadzić jej zapas na okres niskich przepływów w rzece. W latach 1971-73 opracowano dokumentację kolejnego etapu rozbudowy tzw. ZUzW Zwięczyca II. Projektantami byli inżynierowie Marian Hrabiec i Wacław Kordeusz z BPBK w Krakowie. W roku 1980 oddano do eksploatacji ZUzW Zwięczyca II o zdolności produkcyjnej $47500 \mathrm{~m}^{3} / \mathrm{d}$. Równocześnie zrealizowano magistralę $Q 1000 \mathrm{~mm}$ i dwa zbiorniki na Pobitnem o pojemności $3000 \mathrm{~m}^{3}$ każdy. Kolejne dwa zbiorniki o pojemności $3000 \mathrm{~m}^{3}$ każdy przy ul. Krakowskiej oddano do eksploatacji w 1984 roku. W roku 1996 uruchomiono ozonowanie wstępne, a w roku 2010 blok ozonowania wtórnego i filtracji na bioaktywnym węglu (= BAC) [3]. W roku 2011 oddano do eksploatacji zbiornik sieciowy o pojemności $17400 \mathrm{~m}^{3}$. Należy podkreślić rolę BPBK w Krakowie w rozwoju wodociągów rzeszowskich [1].

Celem pracy jest zaprezentowanie istniejących w latach 80-tych XX wieku koncepcji zaopatrzenia Rzeszowa w wodę. Dobowe zużycie wody dochodziło nawet do $110000 \mathrm{~m}^{3} / \mathrm{d}$, co przekraczało zdolności produkcyjne trzech ZUzW $\left(91500 \mathrm{~m}^{3} / \mathrm{d}\right)$ i możliwości poboru wody z rzeki Wisłok przy stanach niżówkowych. Przemiany społeczno-polityczne w kraju (urealnienie ceny wody) na początku lat 90-tych XX wieku doprowadziły do ponad dwukrotnego spadku zużycia wody w mieście. Opracowane koncepcje stały się nieaktualne, a z czasem zapomniane.

\section{Stan istniejący}

Obecnie miasto Rzeszów dysponuje dwoma ujęciami wody powierzchniowej z rzeki Wisłok i taką samą liczbą zakładów uzdatniania wody (ZUzW) o łącznej zdolności produkcyjnej $84000 \mathrm{~m}^{3} / \mathrm{d}$. Poszczególne ZUzW mają następujące wydajności [4]:

- ZUzW Zwięczyca I - $36500 \mathrm{~m}^{3} / \mathrm{d}$

- ZUzW Zwięczyca II - $47500 \mathrm{~m}^{3} / \mathrm{d}$.

Dobowa produkcja wody w okresach maksymalnego dobowego zapotrzebowania wynosi obecnie $46000 \mathrm{~m}^{3} /$ d. Uzdatnianie wody składa się z typowych pro- 
cesów jednakowych we wszystkich ZUzW. Są to: ozonowanie wstępne, koagulacja siarczanem glinu, filtracja pospieszna grawitacyjna, ozonowanie pośrednie, filtracja bioaktywnym węglem granulowanym oraz dezynfekcja dwutlenkiem chloru [3]. Łączna objętość wody czystej w sześciu zbiornikach wyrównawczych na sieci wynosi $33600 \mathrm{~m}^{3}$. Dostawa wody dla odbiorców odbywa się siecią o łącznej długości około $895 \mathrm{~km}$, w tym:

- sieć magistralna - 49,8 km,

- sieć rozdzielcza - 520, $5 \mathrm{~km}$,

- podłączenia domowe $324,7 \mathrm{~km}$.

W eksploatacji znajduje się 17 wolno stojących hydroforni osiedlowych, w tym 3 pompownie strefowe. Ilość wody dostarczanej poszczególnym odbiorcom przedstawia się następująco:

- dla gospodarstw domowych - 53\%

- dla przemysłu $-29 \%$

- dla pozostałych odbiorców - $18 \%$

Na przełomie lat 80/90 XX wieku wykorzystując system telemetrycznego przekazu informacji z obiektów sieciowych wdrożono opracowany program komputerowy przez zespół pod kierownictwem dr hab. inż. Krzysztofa Knapika z Politechniki Krakowskiej, który pozwoli na optymalizację pracy systemu wodociągowego miasta z wykorzystaniem modelu czasoprzestrzennego ISYDYW.

\section{Perspektywy zaopatrzenia Rzeszowa w wodę}

Zasoby wodne rzeki Wisłok określono na $\mathrm{SNQ}=2,60 \mathrm{~m}^{3} / \mathrm{s}$. Natężenie przepływu nienaruszalnego $0,75 \mathrm{~m} 3 / \mathrm{s}$. W 1988 roku pobór wody z rzeki Wisłok wynosił [5]:

- pobór średni - $0,98 \mathrm{~m}^{3} / \mathrm{s}$

- pobór maksymalny $-1,11 \mathrm{~m}^{3} / \mathrm{s}$.

Obecnie (2014 rok) wynosi odpowiednio $0,45 \mathrm{~m}^{3} / \mathrm{s}$ i $0,54 \mathrm{~m}^{3} / \mathrm{s}$.

Badania na perspektywę roku 2025 obejmowały poszukiwanie sposobów zwiększenia zasobów dyspozycyjnych rzeki Wisłok lub innych źródeł wody dla miasta. W latach 80 - tych XX wieku podjęte zostały prace projektowe zmierzające w dwóch kierunkach:

- przerzut wody z rzeki San,

- wykorzystanie wód wgłębnych w pobliżu Rzeszowa,

- zapatrzenie w wodę aglomeracji rzeszowskiej, w skład której będą w przyszłości wchodzić miasta: Rzeszów, Tyczyn, Głogów i Łańcut,

- wyrównanie zasobów w rzece Wisłok ze zbiornika w Besku jest znikome z powodu małej pojemności zbiornika i ujęcia z niego wody dla wodociągu grupowego Krosno-Iwonicz-Rymanów,

- retencjonowanie zasobów wód powierzchniowych rzeki Wisłok w celu zwiększenia zasobów dyspozycyjnych. 
Według Hydroprojektu dla zlikwidowania deficytu wód powierzchniowych dla użytkowników w rejonie Rzeszowa proponuje się budowę następujących zbiorników wodnych [2]:

- Zbiornik Tyczyn na rzece Strug, $\mathrm{Vc}=2,8 \mathrm{mln} \mathrm{m}^{3}$, wys. piętrzenia $13 \mathrm{~m}$,

- Zbiornik Strzyżów na rzece Stobnica, $\mathrm{Vc}=4,5 \mathrm{mln} \mathrm{m}^{3}, \mathrm{H}=8,5 \mathrm{~m}$,

- Zbiornik Rudawka Rymanowska na rzece Wisłok, Vc = 14,6 $\mathrm{mln}^{3}$, $\mathrm{H}=16,5 \mathrm{~m}$.

Na rzece San przewiduje się dwa zbiorniki:

- Zbiornik Niwistka - Dynów, $\mathrm{Vc}=3,21 \mathrm{mln} \mathrm{m}^{3}, \mathrm{H}=28 \mathrm{~m}$

- Zbiornik Krasiczyn, $\mathrm{Vc}=2,92 \mathrm{mln} \mathrm{m}^{3}, \mathrm{H}=25 \mathrm{~m}$.

\section{Zaopatrzenie Rzeszowa $w$ wodę $w$ oparciu o przerzut $z$ rzeki San - perspektywa na 2025 rok}

Koncepcja alternatywnego zaopatrzenia w wodę Rzeszowa [5]:

\section{Wariant I}

Produkcja wody w ZUzW Zwięczyca I i II na bazie wody z rzeki Wisłok w ilości $1 \mathrm{~m}^{3} / \mathrm{s}$. Przerzut wody podczyszczonej z Sanu i uzdatnianie jej w ZUzW Zwięczyca III o zdolności produkcyjnej $0,8 \mathrm{~m}^{3} / \mathrm{s}$.

Przerzut wody w wariancie 1A przewidywał tranzyt okresowy (kompensacyjny) w ilości wynikającej z sytuacji hydrologicznej rzeki Wisłok.

Przerzut wody $\mathrm{w}$ wariancie $1 \mathrm{~B}$ przewidywał stały tranzyt wody w ilości nie mniejszej niż $0,15 \mathrm{~m}^{3} / \mathrm{s}$, możliwością zwiększenia do $0,8 \mathrm{~m}^{3} / \mathrm{s}$.

Analizy finansowe wykonane w oparciu o bilanse energetyczne, hydrauliczne i ruchowe pokazywały wyższość wariantu 1B nad 1A.

\section{Wariant II}

Produkcja wody w ZUzW Zwięczyca I i II w ilości $1 \mathrm{~m}^{3} / \mathrm{s}$ oraz w ZUzW Niwiska-Dynów w ilości $0,9 \mathrm{~m}^{3} / \mathrm{s}$. Przerzut wody czystej do Rzeszowa w ilości $0,7 \mathrm{~m}^{3} / \mathrm{s} \mathrm{z}$ możliwością zaopatrzenia w wodę gmin na trasie transportu w ilości $0,2 \mathrm{~m}^{3} / \mathrm{s}$. Wariant ten daje możliwość zaopatrzenia w wodę Rzeszowa $\mathrm{z}$ dwóch niezależnych źródeł, co znacząco podnosi aspekt niezawodności dostawy wody do odbiorców w mieście.

Punktem wyjściowym do opracowania wariantów przerzutu wody z Sanu do Rzeszowa był fakt, że czas trwania niedoborów wody oszacowano na 52 doby w roku ( w odniesieniu do możliwości poboru z rzeki Wisłok w ilości SNQ przepływ nienaruszalny $=2,60-0,75=1,85 \mathrm{~m}^{3} / \mathrm{s}$ ) z trendem jego pogłębiania wraz z rozwojem miasta w perspektywie roku 2050. Koncepcja techniczna przesyłu wody uzdatnionej:

- jaz na rzece San, $q=2,20 \mathrm{~m}^{3} / \mathrm{s}$,

- pompownia wody surowej (niskiego ciśnienia), 
- rurociąg wody surowej $~ 1000 \mathrm{~mm}-5 \mathrm{~km}$ (do ZUzW w Niwistce),

- pompownia wysokiego ciśnienia,

- magistrala dosyłowa do Piątkowej 2 x Q $900 \mathrm{~mm}$ o długości $22 \mathrm{~km}$,

- zbiorniki dyspozycyjne na trasie magistrali w Piątkowej V $=30000 \mathrm{~m}^{3}$ (dział wód),

- magistrala 2 x Q 900 mm Piątkowa - Zwięczyca o długości 15,2 km i Piątkowa - Pobitno o długości 19,4 km,

- rozbudowa zbiorników na Pobitnem V $=20000 \mathrm{~m}^{3}$,

- rozbudowa zbiorników Baranówka Vo $=30000 \mathrm{~m}^{3}$,

- modernizacja ZUzW Zwięczyca I i II (ozon, filtry węglowe).

Technologia ZUzW przedstawia się następująco:

- zbiorniki uśredniające - osadniki,

- koagulacja (siarczan glinu, krzemionka aktywna, węgiel pylisty, wapno), filtry piaskowo-antracytowe, ozonowanie wstępne i pośrednie, filtry $\mathrm{z}$ węglem aktywnym, dezynfekcja chlorem.

Pojemność wyrównawcza jazu dla ujęcia wody w Dynowie - Niwistce wynosić będzie $150000 \mathrm{~m}^{3}$. Należy zapewnić odpływ minimalny z kaskady Solina Myczkowce na $6 \mathrm{~m}^{3} / \mathrm{s}$ [5].

\section{Rozbudowa wodociągu m. Rzeszowa - ujęcie wód podziem- nych Bratkowice - Zaczernie}

Realizację ujęcia wód wgłębnych dla miasta Rzeszowa przewiduje się w II etapach [2].

\section{Etap I}

Ujęcie wody w rejonie Miłocina o łącznej wydajności 8 studni, wynoszącej $300 \mathrm{~m}^{3} / \mathrm{h}=7200 \mathrm{~m}^{3} / \mathrm{d}$. Woda nie wymaga uzdatniania. Odległość przesyłu wynosi około $5 \mathrm{~km}$. Równocześnie w tym etapie przewiduje się rozbudowę zbiorników wyrównawczych o wielkości 2 x $15000 \mathrm{~m}^{3}$.

\section{Etap II}

Ujęcie wody w rejonie Bratkowic i Rudnej z 13 studni o łącznej wydajności $500 \mathrm{~m}^{3} / \mathrm{h}=12000 \mathrm{~m}^{3} / \mathrm{d}$. Woda wymaga uzdatniania z uwagi na zwiększoną zawartość żelaza i manganu. Odległość przesyłu wynosi około $15 \mathrm{~km}$.

I etap obejmuje studnie od S-1 do S -8 o łącznej wydajności eksploatacyjnej $\mathrm{Q}=390,1 \mathrm{~m}^{3} / \mathrm{h}=0,108 \mathrm{~m}^{3} / \mathrm{h}=9362 \mathrm{~m}^{3} / \mathrm{d}$. Woda $\mathrm{z}$ tych studni nie wymaga uzdatniania, tylko poddania dezynfekcji chlorem. Całość to 21 studni o wydajności Q $=21120 \mathrm{~m}^{3} / \mathrm{d}=880,7 \mathrm{~m}^{3} / \mathrm{h}=0,244 \mathrm{~m}^{3} / \mathrm{s}$.

Studnie S-9 $\div$ S-21 to II etap - usunięcie żelaza i manganu. Wydajności eksploatacyjne studni zostały określone w zatwierdzonej dokumentacji geologicznej w kat. B przedstawiono w tab. 1. 
Tabela 1. Charakterystyka studni Bratkowice - Zaczernie

Table 1. Characteristics of Bratkowice - Zaczernie well

\begin{tabular}{|c|c|c|c|}
\hline Nr studni & $\begin{array}{l}\text { Qeksp. } \\
{\left[\mathrm{m}^{3} / \mathrm{h}\right]}\end{array}$ & $\begin{array}{c}\text { Depresja } \\
{[\mathrm{m}]}\end{array}$ & $\begin{array}{l}\text { Głębokośść } \\
{[\mathrm{m}]}\end{array}$ \\
\hline S-1 & 51,2 & 4,90 & 10,65 \\
\hline S-2 & 54,2 & 4,30 & 11,00 \\
\hline S-3 & 35,7 & 5,40 & 10,10 \\
\hline S-4 & 37,4 & 5,30 & 6,40 \\
\hline S-5 & 52,7 & 3,80 & 11,20 \\
\hline S-6 & 60,0 & 5,50 & 7,80 \\
\hline S-7 & 60,5 & 5,60 & 6,70 \\
\hline \multirow[t]{2}{*}{ S-8 } & 38,4 & 6,10 & 8,00 \\
\hline & $\sum Q=390,1 \mathrm{~m}^{3} / \mathrm{h}$ & & \\
\hline S-9 & 33,4 & 5,60 & 8,90 \\
\hline S-10 & 48,1 & 5,80 & 8,33 \\
\hline S-11 & 38,5 & 4,10 & 5,40 \\
\hline S-12 & 38,5 & 5,15 & 7,40 \\
\hline S-13 & 39,5 & 4,55 & 7,10 \\
\hline S-14 & 51,5 & 5,00 & 5,70 \\
\hline S-15 & 38,1 & 4,40 & 4,85 \\
\hline S-16 & 29,7 & 5,90 & 6,00 \\
\hline S-17 & 25,3 & 4,70 & 13,30 \\
\hline S-18 & 31,0 & 4,50 & 9,30 \\
\hline S-19 & 41,0 & 4,40 & 10,95 \\
\hline S-20 & 32,0 & 3,70 & 10,50 \\
\hline \multirow[t]{2}{*}{ S-21 } & 44,0 & 6,00 & 20,80 \\
\hline & $\sum Q=490,6 \mathrm{~m}^{3} / \mathrm{h}$ & & \\
\hline Razem & $\begin{array}{c}880,7 \mathrm{~m}^{3} / \mathrm{h}=21120 \\
\mathrm{~m}^{3} / \mathrm{d}\end{array}$ & & \\
\hline
\end{tabular}

W każdej studni będzie pompa głębinowa pracująca $\mathrm{z}$ wydajnością nie przekraczającą wydajności eksploatacyjnej w kat. B. Wszystkie pompy pracują na wspólny rurociąg wody surowej. Na rys. 1 pokazano schemat ujęcia wody ze studni nie wymagających jej oczyszczenia (I etap).

Uruchomienie studni 9-21 przewidywano w drugim etapie inwestycyjnym, który obejmował także oczyszczanie wody z nadmiaru żelaza poprzez napowietrzanie i filtrację piaskową.

Pompownia wysokiego ciśnienia tłoczy wodę przewodem $Q 400 \mathrm{~mm}$ do istniejącej sieci magistralnej $\otimes 600 \mathrm{~mm}$ miasta Rzeszowa i wysokości podnoszenia $\mathrm{H}=38,2 \mathrm{~m}$. 


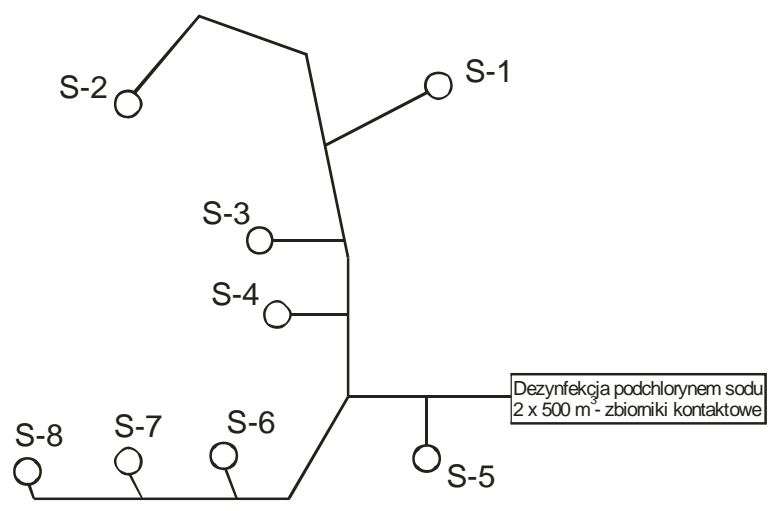

Rys. 1. Schemat ujęcia wody ze studni 1-8

Fig. 1. Diagram of water intake from wells 1-8

\section{Podsumowanie}

W drugiej połowie lat 80-tych XX wieku SZZW Rzeszowa miał charakter deficytowy - popyt na wodę wodociągową przewyższył jej podaż. W stanach niżówkowych rzeki Wisłok w przekroju ujęcia w Zwięczycy wyczerpały się możliwości zwiększania poboru wody dal celów wodociągowych. Stan ten uruchomił prace nad nowymi źródłami dostawy wody do miasta, tym bardziej, że ówczesna perspektywa 2030 roku wskazywała, że Rzeszów będzie liczył 400000 mieszkańców. Planowana metropolia miała obejmować podrzeszowskie miasteczka: Głogów Młp., Tyczyn i Łańcut.

Zrównoważenie SZZW miasta oparto o dwie koncepcje. Pierwsza dotyczyła wykorzystania wód podziemnych. Druga wskazywała na konieczność przerzutu wody z rzeki San, przez dział wód Sanu i Wisłoka do Rzeszowa. Wiązało się to $\mathrm{z}$ budową zbiornika retencyjnego na rzece San w miejscowości Niwiska koło Dynowa.

Końcowa hierarchia działań na rzecz likwidacji deficytu wody wodociągowej dla miasta Rzeszowa preferowała inwestycje związane $\mathrm{z}$ wodami podziemnymi. Dopiero w perspektywie roku 2025 miano sięgnąc po wody powierzchniowe z rzeki San.

Realia przejścia z gospodarki nakazowo-rozdzielczej na gospodarkę rynkową spowodowały, że SZZW Rzeszowa stał się systemem nadmiarowym podaż wody wodociągowej w sposób znaczący zaczął przewyższać na nią popyt. Stało się to bez udziału jakichkolwiek inwestycji, a nawet doprowadziło do zamknięcia starego ZUzW Rzeszów w 1995 roku. Mechanizmy gospodarki rynkowej (urealnienie ceny wody, eliminacja z rynku usług i działalności produkcyjnej o charakterze wodochłonnym) były jedyną przyczyną drastycznego spadku zużycia wody wodociągowej. Spowodowało to zaniechanie prac zwiększających dostawę wody do miasta. 
Działania MPWiK Rzeszów alternatywnie skupiły się na programie kompleksowej poprawy jakości wody do spożycia poprzez modernizację ZUzW Zwięczyca I i II oraz budowę sieciowego zbiornika wody czystej o V $=17300 \mathrm{~m}^{3}$.

Należy podkreślić celność koncepcji technologicznych uzdatniania wody, w szczególności przewidzenie procesu ozonowania pośredniego - filtracja na granulowanym węglu aktywnym.

\section{Literatura}

[1] Fiszer J.: Ocena wybranych systemów wodociągów i kanalizacji oraz gospodarki wodnej i ochrony wód przed zanieczyszczeniami, Wydawnictwo Politechniki Krakowskiej, Kraków 2005.

[2] Program zaopatrzenia w wodę i odprowadzania ścieków województwa rzeszowskiego do 2015 r., Biuro projektów Budownictwa Komunalnego w Rzeszowie, Rzeszów 1981 (maszynopis).

[3] Rak J.; Tchórzewska-Cieślak B.; Tunia A.: Realizacja programu kompleksowej poprawy jakości wody do spożycia dla miasta Rzeszowa, Zeszyty Naukowe Politechniki Rzeszowskiej Budownictwo i Inżynieria Środowiska z.32, Rzeszów 2000, s. 353-361.

[4] Rak J.; Wieczysty A.; Kucharski B.; Latawiec E.: Program kompleksowej poprawy jakości wody do picia dla miasta Rzeszowa - ocena niezawodnościowa, Mat. Konf. Bezpieczeństwo i niezawodność działania systemów gazowych, wodociągowych, kanalizacyjnych i centralnego ogrzewania, Zakopane 1997, s. 133-144.

[5] Wieczysty A.: Koreferat do programu zaopatrzenia w wodę miasta Rzeszowa do roku 2015, Kraków 1988 (maszynopis).

\section{FORGOTTEN CONCEPTS OF RZESZOW WATER SUPPLY}

\section{S u m m a r y}

Rzeszow waterworks dates back of about 80 years. Currently, the collective water supply system has excess production capacity. For this reason, in the early $90 \mathrm{~s}$ - of the twentieth century the first Water Treatment Plant, operating since 1934, was closed. However in the early 80s - of the twentieth century, the city consumed more water than the production capacity of three Water Treatment Plant. Study was undertaken to investigate the elimination of the existing water deficits. It was not possible to further increase the water intake from the Wisłok river. Two concepts have been developed as an alternative water supply of Rzeszow from two new sources: - groundwater intakes of 21 existing wells drilled in suburban towns Zaczernie - Bratkowice,

- transfer of water from the River San from the tank aimed to be built in the village Niwiska near Dynów. These projects were not realized, although the 21 wells have been completed and the water from it was tested during the pumping test.

Keywords: water supply, design concepts, the characteristics of the water supply system, alternative water supply

Przestano do redakcji: $18.02 .2015 \mathrm{r}$.

Przyjęto do druku: 30.10 .2015 r.

DOI: $10.7862 / \mathrm{rb} .2015 .120$ 